\title{
Linear free energy relationships in halogen bonds $\uparrow$
}

Cite this: CrystEngComm, 2013, 15, 3178

\author{
Ibon Alkorta, ${ }^{*}$ Goar Sánchez-Sanz and José Elguero
}

\begin{abstract}
Four models of halogen bonds were used to quantify this bond using the DFT B97D/6-311+G(d) computational level: para-substituted iodobenzenes, para- and meta-substituted bromobenzenes complexed with three simple Lewis bases $\left(\mathrm{NH}_{3}, \mathrm{NCH}\right.$ and $\left.\mathrm{CNH}\right), 1$-bromo-4-substituted-bicyclo[2.2.2]octanes with $\mathrm{NH}_{3}$ and 3- and 4-substituted pyridines complexed with $\mathrm{BrCl}$ and $\mathrm{BrF}$. In addition, the combination of the para-substituted bromobenzenes with the 4-substituted pyridines has been studied. A total of 459 complexes have been optimized and are discussed in the present article. The energetic and geometric results have been analyzed based on the properties of the substituents and the isolated molecules involved in the interaction. The Hammett-Taft parameters provide reasonable correlations with the interaction energies. However, excellent correlations are obtained in all the cases when the electrostatic properties of the two molecules involved in the interaction are considered $\left(R^{2}>0.99\right)$.
\end{abstract}

Received 31st October 2012,

Accepted 21st December 2012

DOI: $10.1039 /$ c2ce26786a

www.rsc.org/crystengcomm

scales. ${ }^{16}$ They reported experimental and computed values for

\section{Introduction}

The old and fundamental concept of a hydrogen bond (HB), which dates from $1920,{ }^{1}$ has been extended to other weak interactions such as dihydrogen bonds, ${ }^{2}$ halogen bonds (XB), ${ }^{3}$ chalcogen bonds ${ }^{4}$ and pnictogen bonds. ${ }^{5}$ Amongst these bonds, halogen bonds have been known for a long time ${ }^{6}$ and are the most studied, to the point that a book has been devoted to them. ${ }^{7}$ In it, there are chapters concerning microwave spectroscopy (chapter 2), crystallography (chapter 4) and theoretical calculations (chapter 1). Closely related to halogen bonds is the concept of a $\sigma$-hole introduced by Politzer. $^{8}$

The possibility that the interaction energy between monomers correlates with substituent effects has been explored in the case of the thermodynamic acidity of meta- and parasubstituted benzoic acids, ${ }^{9}$ the basicity of 3- and 4-substituted pyridines,${ }^{10}$ hydrogen-bonded acidity (HBA) and basicity $(\mathrm{HBD})^{11}$ and many other properties that are gathered under the names of linear free energy relationships (LFER), ${ }^{12}$ extrathermodynamic relationships (ETR) ${ }^{13}$ and correlation analysis in chemistry (CAC) ${ }^{14}$

Surprisingly, there are very few previous works on this kind of approach for halogen bonds. The oldest one is by Person, Golton and Popov who showed that $\log K$ values for complexes of nitriles with ICl, IBr and $\mathrm{I}_{2}$ present linear relationships with Taft $\sigma^{*} \cdot{ }^{15}$ Related publications belong to a very well known group in the field of hydrogen bond basicity and acidity

Instituto de Quimica Medica, IQM-CSIC, Calle Juan de la Cierva, 3, Madrid, Spain. E-mail: ibon@iqm.csic.es; http://are.iqm.csic.es; Fax: +34915644853

$\dagger$ Electronic supplementary information (ESI) available: tables with the interaction energy, intermolecular distances and descriptors of the isolated monomers. Complete list of the equations discussed in the article. See DOI: $10.1039 / \mathrm{c} 2 \mathrm{ce} 26786 \mathrm{a}$ the diiodine scale $\mathrm{p} K_{\mathrm{BI} 2}$ and its behavior towards a large variety of bases, including 3 - and 4-substituted pyridines, which show very good correlations with Taft's $\sigma_{\mathrm{F}}$ and $\sigma_{\mathrm{R}}{ }^{17}$

Bauzá, Quiñonero, Frontera and Deyà published a paper in 2011 that was the first attempt to correlate calculated interaction energies of halogen bonded complexes with Hammett $\sigma$ values. ${ }^{18}$ They reported results concerning the complexes in Scheme 1 (7 points, $0.967<R^{2}<0.982$ ).

Murray, Politzer et al. have shown that the electrostatic potential in the molecular surfaces of isolated halo-derivatives is well correlated with the interaction energies of a small series of halogen bonded complexes. ${ }^{19}$

The aim of the present work is to determine the interaction energies corresponding to the five equilibria depicted in Scheme 2, which correspond to para-substituted iodobenzenes and para- and meta-substituted bromobenzenes (1) and (2) (Model 1), to bromo-bicyclo[2.2.2] octanes (3) (Model 2) and to 3- and 4-substituted pyridines (4) and (5) (Model 3). In a fourth section (Model 4) we will examine the double-Hammett

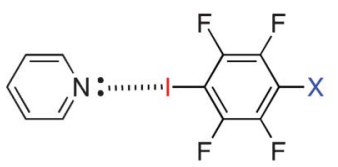<smiles>[Y]c1cc[n+]([Hg]c2c(F)c(F)cc(F)c2F)cc1</smiles>
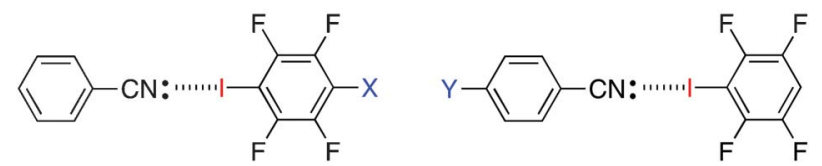

Scheme 1 Complexes studied in ref. 18. 


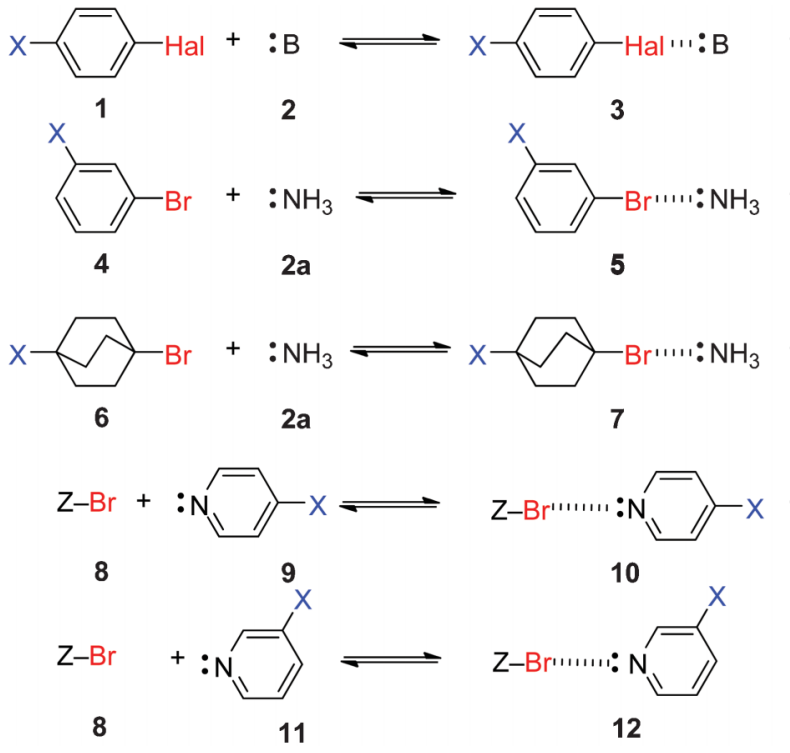

(1)

Scheme 2 Equilibria involving halogen bonds. Hal stands for iodine and bromine, $\mathrm{B}$ for $\mathrm{NH}_{3}, \mathrm{NCH}$ and $\mathrm{CNH}$, and $\mathrm{Z}$ for $\mathrm{F}$ and $\mathrm{Cl}$.

relationships when both the Lewis acid and the Lewis base bear substituents.

Three bases B (2) were used: ammonia (2a), hydrogen cyanide (2b) and hydrogen isocyanide (2c). The first two are $\mathrm{N}$ bases and the third is a $\mathrm{C}$ base.

Amongst the large collection of substituent constants, ${ }^{12,14,20}$ we have selected the most commonly used ones, Hammett's $\sigma_{\mathrm{p}}$ and $\sigma_{\mathrm{m}}{ }^{21}$ for para and meta-substituted benzene derivatives but extended them to heteroaromatic compounds, and Taft's biparameter equation separating through space field effects, $\sigma_{\mathrm{F}}$, from resonance effects, $\sigma_{\mathrm{R}} ; \sigma_{\mathrm{F}}$ and $\sigma_{\mathrm{R}}$ being common to para and meta-substituted benzenes. For saturated systems, particularly for bicyclo[2.2.2]octanes like 6, only through space, $\sigma_{\mathrm{F}}$, and through $\sigma$-bond, $\sigma_{\mathrm{I}}$, effects are operative. Note that $\sigma_{\mathrm{F}}$ and $\sigma_{\mathrm{I}}$ are roughly proportional (slope 0.996, $n=16, R^{2}=0.978$ ). A list with all the equations discussed in the manuscript can be found in the ESI. $\dagger \sigma_{\text {I values }}$ of the selected substituents have been taken from a web page (Table 1), ${ }^{22}$ while $\sigma_{\mathrm{F}}$ and $\sigma_{\mathrm{R}}$ are from the Hansch, Leo and Taft review. ${ }^{17}$

In addition to the Hammett-Taft LFER approach, we intend to examine other theoretical outputs in their relationships with interaction energies. Amongst them the $\mathrm{C}-\mathrm{Br}$ bond length, the radius of the bromine atom, the $\sigma$-hole of the bromine atom and the MEP minima of the electron donor have been considered. There has been much interest in connecting empirical substituent constants with different computed values. The main effort has been done by Exner and Böhm on the one hand and by Krygowski and Oziminski on the other. Exner and Böhm used DFT calculations of the interaction energies and the inductive effects. ${ }^{23-25}$ Krygowski and Oziminski used Bader AIM analysis, natural population analysis and NBO analysis to discuss the Hammett $\sigma$
Table 1 The substituent constants of the 17 selected groups

\begin{tabular}{llllll}
\hline Group & $\sigma_{\mathrm{p}}$ & $\sigma_{\mathrm{m}}$ & $\sigma_{\mathrm{F}}$ & $\sigma_{\mathrm{R}}$ & $\sigma_{\mathrm{I}}$ \\
\hline $\mathrm{NO}_{2}$ & 0.78 & 0.71 & 0.64 & 0.16 & 0.76 \\
$\mathrm{CN}$ & 0.66 & 0.56 & 0.54 & 0.18 & 0.53 \\
$\mathrm{CF}_{3}$ & 0.54 & 0.43 & 0.46 & 0.09 & 0.42 \\
$\mathrm{COCH}_{3}$ & 0.50 & 0.38 & 0.25 & 0.16 & 0.29 \\
$\mathrm{CO}_{2} \mathrm{H}$ & 0.45 & 0.37 & - & - & 0.39 \\
$\mathrm{CHO}$ & 0.42 & 0.35 & 0.35 & 0.23 & 0.25 \\
$\mathrm{Cl}$ & 0.23 & 0.37 & 0.43 & -0.16 & 0.47 \\
$\mathrm{Br}$ & 0.23 & 0.39 & 0.49 & -0.16 & 0.50 \\
$\mathrm{SH}$ & 0.15 & 0.25 & 0.27 & -0.13 & 0.26 \\
$\mathrm{~F}$ & 0.06 & 0.34 & 0.57 & -0.33 & 0.52 \\
$\mathrm{H}$ & 0.00 & 0.00 & 0.00 & 0.00 & 0.00 \\
$\mathrm{SCH}_{3}$ & 0.00 & 0.15 & 0.20 & -0.15 & 0.23 \\
$\mathrm{CH}$ & -0.17 & -0.07 & -0.01 & -0.13 & -0.04 \\
$\mathrm{OCH}_{3}$ & -0.27 & 0.12 & 0.30 & -0.43 & 0.27 \\
$\mathrm{OH}$ & -0.37 & 0.12 & 0.32 & -0.43 & 0.29 \\
$\mathrm{NH}_{2}$ & -0.66 & -0.16 & 0.09 & -0.48 & 0.12 \\
$\mathrm{~N}\left(\mathrm{CH}_{3}\right)_{2}$ & -0.83 & -0.15 & 0.17 & -0.56 & 0.06 \\
& & & & & \\
\hline
\end{tabular}

coefficients. $^{26-28}$ Suresh et al. have calculated molecular electrostatic potentials (MEP), finding linear correlations between $\sigma_{\mathrm{I}}$ and $V_{\min }$ (the minimum of MEP). ${ }^{29}$ Platts has studied the relationship between the parameter calculated using $a b$ initio methods and the experimentally derived $\mathrm{p} K_{\mathrm{HB}}{ }^{30}$

\section{Computational details}

The geometry of the systems has been fully optimized with the B97D DFT functional, ${ }^{31}$ which incorporates an explicit treatment of the dispersion interactions. The standard 6-311+G(d) basis set $^{32}$ has been used for all the atoms except iodine, where the LANL2DZ basis set $^{33}$ has been used. Frequency calculations have been carried out in all cases to confirm that the structures obtained correspond to energetic minima. The interaction energy has been corrected for the inherent basis set superposition error (BSSE) using the counterpoise method. ${ }^{34}$ All these calculations have been performed with the Gaussian 09 package. ${ }^{35}$

The molecular electrostatic potential (MEP) of the isolated interacting molecules has been fully characterized. The values of the MEP near a molecule may be positive or negative in a given region. The negative MEP are indicative of regions where electrophiles will be attracted, in particular to that where the MEP is a minimum. These minimum values can be located using minimization algorithms as those implemented in the Gaussian 09 program. In contrast, very steep maximum MEP values are located in all the nuclear positions, which limit their use as a predictive tool. On the other hand, the plotted MEP on a molecular surface, such as the van der Waals surface, provides regions where nucleophiles will approach the molecule. This analysis has been carried out using the WFA program. $^{36}$

Three additional parameters have been used to characterize the monomers in this study, the bromine radius in the direction of the interaction, the $\sigma$-hole of the bromine nucleus 


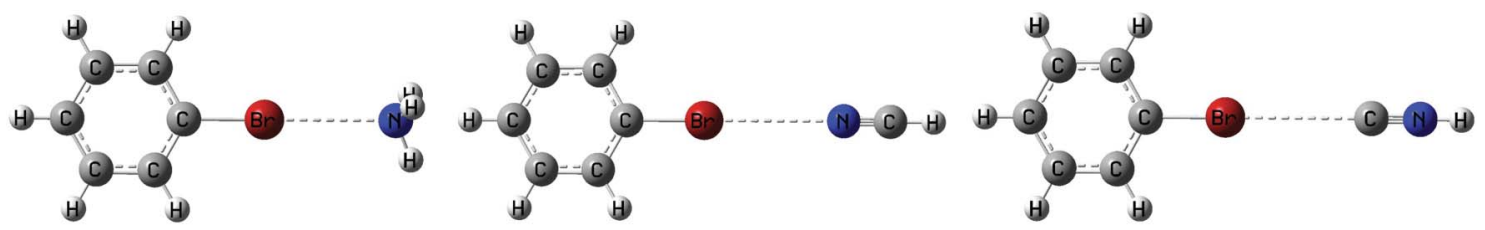

Fig. 1 Optimized geometries of the complexes of 1-bromobenzene with ammonia, hydrogen cyanide and hydrogen isocyanide at the B97D/6-311+G(d) computational level.

and the MEP minima of the electron donors. The Br radius has been calculated as the distance from the $\mathrm{Br}$ atom to the $0.001 \mathrm{e}$ bohr $^{-3}$ isosurface along the $\mathrm{C}$-Br direction and the $\sigma$-hole has been obtained as the electrostatic potential value in the point of the isosurface used to calculate the $\mathrm{Br}$ radius. The $0.001 \mathrm{e}$ bohr ${ }^{-3}$ isosurface has been used since it has been shown to resemble the experimental van der Waals surface. ${ }^{37}$ The electron density has been calculated and analyzed with the AIMPAC and AIMAll programs. ${ }^{38,39}$

\section{Results and discussion}

\section{Model 1. para and meta-substituted 1-bromobenzenes}

The complexes formed between the para-substituted 1-iodinebenzene and the para- and meta-substituted 1-bromobenzene with ammonia, hydrogen cyanide and hydrogen isocyanide show a linear disposition of the $\mathrm{C}-\mathrm{Hal} \cdots \mathrm{X}$ atoms $(\mathrm{Hal}=\mathrm{Br}$ and I) very close to $180^{\circ}$ in all the cases. The smallest value found is $177.6^{\circ}$ (see Fig. 1 for the complexes of the parent compound with each of the electron donor bases). The intermolecular distance of the complexes formed between para and metasubstituted benzenes and the three bases considered $\left[\mathrm{NH}_{3}\right.$ (2a), $\mathrm{NCH}(\mathbf{2 b})$ and $\mathrm{CNH}(\mathbf{2 c})]$ are reported in Table SI of the ESI. $\nmid$ The most relevant interatomic distance of the complexes is the Hal $\cdots \mathrm{X}$ distance, $\mathrm{X}=\mathrm{N}\left(\mathrm{NH}_{3}, \mathrm{NCH}\right)$ and $\mathrm{X}=\mathrm{C}(\mathrm{CNH})$ (Table S1, ESI $\dagger$ ). This distance ranges between 3.05 and $3.21 \AA$ in the complexes with $\mathrm{NH}_{3}$ and the values of the $p$ - and $m$ substituted bromobenzenes and those of the $p$-iodobenzenes are very similar for the same substituent. The distances in the complexes with $\mathrm{NCH}$ range between 3.39 and $3.50 \AA$ and between 3.45 and $3.57 \AA$ in the ones with $\mathrm{CNH}$. In all the series, the shorter distance corresponds to the nitro derivative while the longest one is associated to the dimethylamino derivative. The intermolecular distances obtained for the $p$ substituted derivatives are highly correlated $\left(R^{2}>0.99\right)$. The correlation obtained between the $\mathrm{NH}_{3}$ complexes of the $p$ substituted (3a) and the $m$-substituted 1-bromobenzenes (5) shows a slightly worse correlation with a $R^{2}$ value of 0.97 .

The uncorrected interaction energies $\left(E_{\mathrm{i}}\right)$ and BSSE corrected $\left[E_{\mathrm{i}}(\mathrm{cp})\right]$ energies of these complexes are reported in Table S2 in the ESI $\dagger$ (the properties of the isolated monomers can be found in Table S3 in the ESI $\dagger$ ). The uncorrected and corrected interaction energies show very good correlations for the five series of compounds $\left(R^{2}>0.999\right)$. The most stable complex in each series corresponds to the nitro derivative while the least stable one is the dimethylamino derivative, in accordance with the tendencies observed in the intermolecular distances. The complexes of the iodobenzene are more stable than the corresponding complexes of the bromobenzene. Concerning the bases, the $\mathrm{NH}_{3}$ complexes are more stable than those of the $\mathrm{NCH}$ and $\mathrm{CNH}$. These results can be rationalized based on the larger polarizability of the iodine atom $v s$. the bromine one and the higher basicity of the $\mathrm{NH}_{3}$ molecule $v s$. the triatomic molecules $\mathrm{NCH}$ and $\mathrm{CNH}$. It is interesting to notice that even though the numerical values are different, the $E_{\mathrm{i}}(\mathrm{cp})$ values obtained for the complexes with the $p$-substituted derivatives are highly correlated $\left(R^{2}>0.999\right)$. Based on the good correlations found for the geometrical parameters and interaction energies for the complexes of the $p$-substituted derivatives with the three bases, it is clear that the effect of a given substituent is independent of the bases considered $\left(\mathrm{NH}_{3}, \mathrm{NCH}\right.$ or $\left.\mathrm{CNH}\right)$ and the halogen involved (Br or I).

Due to the high correlations found in both the energies and geometries with the rest of the series of complexes, and in the discussion of the results obtained in reaction (1), we will limit the analysis to one of the $p$-substituted complexes, those between the bromobenzene derivatives and $\mathrm{NH}_{3}$.

Three properties of the isolated bromo derivatives have been examined (Table S3, ESI $\dagger$ ): the $\mathrm{C}-\mathrm{Br}$ bond distance, the vdW radius of the bromine atom along the $\mathrm{C}-\mathrm{Br}$ direction and the value of the electrostatic potential along the $\mathrm{C}-\mathrm{Br}$ direction in the vdW surface where the $\sigma$-hole is located (Fig. 2).

We have gathered in Table 2 the results obtained when comparing $E_{\mathrm{i}}(\mathrm{cp})\left(\mathrm{Hal}=\mathrm{Br}, \mathrm{B}=\mathrm{NH}_{3}\right)$ with different properties of the substituents, the corresponding isolated bromobenzenes and the geometrical characteristics of the complexes (Table S3, ESI $\dagger$ ). Three sets of complexes have been considered, i) the $p$-substituted; ii) the $m$-substituted and iii) both the para and meta-substituted together. In general, better correlations are obtained for the $p$ - than for the $m$-substituted derivatives, the exceptions being the correlations with the $\sigma_{\mathrm{p}} / \sigma_{\mathrm{m}}$ parameters where the $m$-substituted $R^{2}$ value is larger than in the para-substituted ones (0.942 vs. 0.916, respectively) and when the bromine vdW radius is considered (0.986 vs. 0.982, respectively). The correlations using the values of all the complexes considered together show $R^{2}$ values intermediate to those of the corresponding para and meta relationships except for the $\sigma_{\mathrm{p}} / \sigma_{\mathrm{m}}$ and with the $\mathrm{C}-\mathrm{Br}$ bond distance in the isolated monomers, where the values obtained are worse than those of the two subsets.

Concerning the different properties, the $\sigma_{\mathrm{p}}$ and $\sigma_{\mathrm{m}}$ parameters provide an acceptable estimation of the substituent effect in the studied complexes, showing $R^{2}$ values between 0.85 and 0.94 depending on the set of selected compounds. 

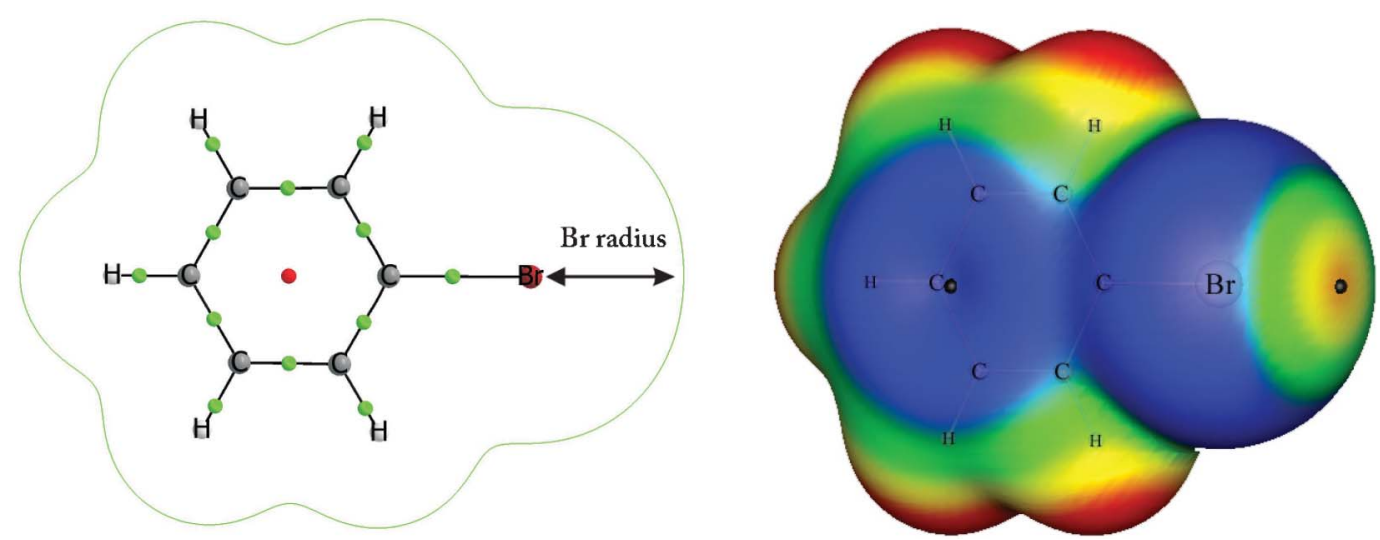

Fig. 2 1-Bromobenzene: left, 0.001 e bohr $^{-3}$ isosurface in the molecular plane with an indication of the Br radius. Right, MEP in the 0.001 e bohr ${ }^{-3}$ isosurface. The $\sigma$-hole position is indicated with a black dot.

The biparametric relationship between $\sigma_{\mathrm{F}}$ and $\sigma_{\mathrm{R}}$ and the interaction energy shows better correlations, with $R^{2}$ values between 0.98 and 0.97 . The intermolecular distances of these complexes show high correlations with the values of the interaction energies ( $R^{2}$ between 0.996 and 0.965).

Experimental reports of the complexation of $\mathrm{I}_{2}$ with a series of bases have allowed for the development of the $\mathrm{p} K_{\mathrm{BI} 2}$ scale, based on the equilibria $A+\mathrm{I}_{2} \rightarrow A: \mathrm{I}_{2} \cdot{ }^{16 b}$ We have found that in ten of the cases, the substituent in the $4 \mathrm{X}$-pyridine: $\mathrm{I}_{2}$ complex is similar to those used in this study. The linear correlation between the $E_{\mathrm{i}}(\mathrm{cp})$ of the corresponding 4-substituted-1iodobenzenes with the $\mathrm{p} K_{\mathrm{BI} 2}$ provides a $R^{2}$ value of 0.93 , which is similar in quality to those obtained for the $\sigma_{\mathrm{p}}$ parameter.

With respect to the properties of the isolated molecules, the value of the $\mathrm{C}-\mathrm{Br}$ bond distance provides good correlations when the para and meta-substituted derivatives are considered independently ( $R^{2}$ values of 0.95 and 0.92 , respectively). The correlation is worse when both groups are considered together $\left(R^{2}\right.$ of 0.85$)$. It should be noted that recently, good relationships between experimental $\mathrm{p} K_{\mathrm{a}}$ values and only one calculated bond distance have been described. ${ }^{40}$ The vdW radius of the bromine atom is highly correlated with the interaction energy, with $R^{2}$ values between 0.96 and 0.986. Finally, excellent correlations $(>0.99)$ are obtained between the values of the electrostatic potential at the $\sigma$-hole and the value of the interaction energy. All this reflects the importance of the electrostatic term in the interaction energy of these complexes.

The fact that eqn (8), (14) and (20) (ESI $\dagger$ ) have less points is due to the lack of $\sigma_{\mathrm{F}}$ and $\sigma_{\mathrm{R}}$ values for the carboxylic group (Table 1).

The possibility of predicting the interaction energy of any combination of a bromobenzene derivative and an electron donor base using the properties of the isolated monomer has been tested for the 68 complexes of the $m$ - and $p$-bromobenzene derivatives and the three bases considered here. The

Table 2 Results obtained for the equation $E_{\mathrm{i}}(\mathrm{cp})\left(\mathrm{NH}_{3}\right)=a_{0}+a_{1}$ property of the $m$ - and $p$-bromobenzene derivatives : $\mathrm{NH}_{3}$ complexes

\begin{tabular}{|c|c|c|c|c|c|c|}
\hline & $\mathrm{N} \cdots \mathrm{Br}$ & $\sigma_{\mathrm{p}} / \sigma_{\mathrm{m}}$ & $\sigma_{\mathrm{F}}+\sigma_{\mathrm{R}}$ & $\mathrm{C}-\mathrm{Br}$ & Br-radius & $\sigma$-hole \\
\hline \multicolumn{7}{|l|}{ para } \\
\hline eqn & (6] & (7) & (8) & (9) & $(10)$ & (11) \\
\hline$n$ & 17 & 17 & 16 & 17 & 17 & 17 \\
\hline$R^{2}$ & 0.996 & 0.916 & 0.982 & 0.950 & 0.982 & 0.999 \\
\hline SD & 0.13 & 0.63 & 0.29 & 0.49 & 0.29 & 0.06 \\
\hline$a_{0}$ & $-197 \pm 3$ & $-8.6 \pm 0.2$ & $-7.9 \pm 0.2$ & $-921 \pm 54$ & $-859 \pm 30$ & $-2.82 \pm 0.05$ \\
\hline $\begin{array}{l}a_{1} \\
\text { meta }\end{array}$ & $60.1 \pm 0.9$ & $-4.5 \pm 0.4$ & $-6.0 \pm 0.4,-5.7 \pm 0.3$ & $474 \pm 28$ & $418 \pm 15$ & $-292 \pm 2$ \\
\hline eqn & $(12)$ & (13) & $(14)$ & $(15)$ & $(16)$ & $(17)$ \\
\hline$n$ & 17 & 17 & 16 & 17 & 17 & 17 \\
\hline$R^{2}$ & 0.965 & 0.942 & 0.974 & 0.925 & 0.986 & 0.99 \\
\hline SD & 0.36 & 0.46 & 0.31 & 0.53 & 0.23 & 0.18 \\
\hline$a_{0}$ & $-170 \pm 8$ & $-7.4 \pm 0.2$ & $-7.7 \pm 0.2$ & $-890 \pm 65$ & $670 \pm 20$ & $-2.5 \pm 0.2$ \\
\hline$a_{1}$ & $51 \pm 3$ & $-7.4 \pm 0.2$ & $-6.4 \pm 0.4,-4.2 \pm 0.3$ & $457 \pm 34$ & $325 \pm 10$ & $-312 \pm 7$ \\
\hline \multicolumn{7}{|c|}{ para + meta } \\
\hline eqn & (18) & (19) & $(20)$ & $(21)$ & $(22)$ & $(23)$ \\
\hline$n$ & 34 & 34 & 32 & 34 & 34 & 34 \\
\hline$R^{2}$ & 0.976 & 0.852 & 0.970 & 0.850 & 0.963 & 0.994 \\
\hline SD & 0.31 & 0.77 & 0.35 & 0.77 & 0.38 & 0.15 \\
\hline$a_{0}$ & $-183 \pm 5$ & $-8.3 \pm 0.1$ & $-7.8 \pm 0.1$ & $-829 \pm 61$ & $-750 \pm 26$ & $-2.68 \pm 0.09$ \\
\hline$a_{1}$ & $56 \pm 2$ & $-5.0 \pm 0.4$ & $-6.2 \pm 0.3,-5.0 \pm 0.3$ & $426 \pm 32$ & $365 \pm 13$ & $-300 \pm 4$ \\
\hline
\end{tabular}


Table 3 Statistical results obtained for the $E_{\mathrm{i}}(\mathrm{cp})=a_{0}+a_{1} \times P_{1}+a_{2} \times P_{2}+a_{12}$ $\times P_{1} \times P_{2}$ model using the $E_{\mathrm{i}}(\mathrm{cp})$ value of the 68 complexes of the bromobenzene derivatives with $\mathrm{NH}_{3}, \mathrm{NCH}$ and $\mathrm{CNH}$

\begin{tabular}{lll}
\hline & $P_{1}=\sigma$-hole & \\
& $P_{2}=$ PA & $\begin{array}{l}P_{1}=\sigma \text {-hole } \\
P_{2}=\text { MEP }\end{array}$ \\
\hline eqn & $(24)$ & $(25)$ \\
$n$ & 68 & 68 \\
$R^{2}$ & 0.927 & 0.998 \\
$\mathrm{SD}$ & 0.86 & 0.11 \\
$a_{0}$ & $21 \pm 5$ & $4.7 \pm 0.2$ \\
$a_{1}$ & $290 \pm 208$ & $-117 \pm 7$ \\
$a_{2}$ & $-0.028 \pm 0.006$ & $60 \pm 2$ \\
$a_{12}$ & $-0.7 \pm 0.3$ & $1470 \pm 70$
\end{tabular}

property that has been used to characterize the corresponding bromobenzene is the value of the $\sigma$-hole. In the case of the bases, two parameters have been tested: the experimental proton affinity $\left(853.6,712.9\right.$ and $772.3 \mathrm{~kJ} \mathrm{~mol}^{-1}$ for $\mathrm{NH}_{3}, \mathrm{NCH}$ and $\mathrm{CNH}$, respectively) ${ }^{41}$ and the value of the MEP minimum associated with the lone pair of the bases that interacts with the halogen atom $\left(-0.1245,-0.0646\right.$ and -0.0679 au for $\mathrm{NH}_{3}$, $\mathrm{NCH}$ and $\mathrm{CNH}$, respectively). The use of the PA to describe the base (eqn (24), ESI $\dagger$ ) provides a correlation with an $R^{2}$ value of 0.93 and a SD of $0.86 \mathrm{~kJ} \mathrm{~mol}^{-1}$, indicating that the stronger the base is, the greater $E_{\mathrm{i}}(\mathrm{cp})$ is. Excellent results $\left(R^{2}=0.998\right.$ and $\mathrm{SD}=0.11 \mathrm{~kJ} \mathrm{~mol}^{-1}$ ) are obtained when the values of the MEP are used in both the bromobenzene derivatives and the base (eqn (25), ESI†), as shown in Table 3.

\section{Model 2. 1-Bromo-4-X-bicyclo[2.2.2]octanes}

The complexes formed between the 4-substituted 1-bromobicyclo[2.2.2] octanes with ammonia present a linear disposition of the $\mathrm{C}-\mathrm{Br} \cdots \mathrm{N}$ atoms, as in the case of the complexes between the bromobenzenes, the smallest angle found between these three atoms being $177.5^{\circ}$ (see Fig. 3 for the optimized geometry of two of the complexes studied in this section). The energetic values and the intermolecular distances of the complexes between the 4-substitued derivatives of 1-bromobicyclo[2.2.2] octane and ammonia are gathered in Table S4 in the ESI. $\dagger$ Some of the properties of the isolated bromo derivatives are included in the same table.

The $E_{\mathrm{i}}(\mathrm{cp})$ values range between $-5.42 \mathrm{~kJ} \mathrm{~mol}^{-1}$ for the $4-\mathrm{NO}_{2}$ derivative to -1.92 for the complex of the parent compound. In accordance with the energetic results, the shortest $\mathrm{Br} \cdots \mathrm{N}$ distance is found in the $4-\mathrm{NO}_{2}$ derivative and the longest in the complex of the parent compounds. The absence of an electron withdrawing group, the benzene in the previous section, increases the vdW radius of the bromine atom and reduces the values of the $\sigma$-hole in the 4-substituted 1-bromobicyclo[2.2.2] octanes when compared to the corresponding bromobenzenes.

The calculated interaction energy corrected with the BSSE is proportional to the uncorrected interaction energy (eqn (26), ESI $\dagger, R^{2}=0.997$, Table 4 ), as in the case of the complexes between halobenzenes and different bases discussed in the previous section. The values of the $\sigma_{\mathrm{F}}$ parameters for the different substituents considered in this work show a $R^{2}$ value of 0.90 with the $E_{\mathrm{i}}$ (cp) (eqn (27), ESI†). Better correlations are obtained using the calculated intermolecular distances (eqn (28), ESI $\left.\dagger, R^{2}=0.98\right)$, the $\mathrm{C}-\mathrm{Br}$ bond distance in the isolated molecules (eqn (29), ESI $\dagger, R^{2}=0.97$ ) and the $\mathrm{Br}$ radius (eqn (30), ESI $\left.\dagger, R^{2}=0.98\right)$. As in the previous case, an excellent correlation is obtained when the values of the MEP in the $\sigma$-hole are used (eqn (31), ESI $\dagger, R^{2}=0.993$ ).

If we compare the $E_{\mathrm{i}}(\mathrm{cp})$ values corresponding to equilibria (1) ( $\mathrm{Hal}=\mathrm{Br}$ and $\mathrm{B}=\mathrm{NH}_{3}$ ) and (3) of Scheme 2, they are weakly related ( $\left.n=17, R^{2}=0.74\right)$. Alternatively, a relationship using three parameters can be proposed using eqn (32) and (33):

$$
\begin{gathered}
E_{\mathrm{i}}(\mathrm{cp})(\text { benzenes })=-(7.9 \pm 0.2)-(4.1 \pm 1.5) \sigma_{\mathrm{F}}- \\
(5.6 \pm 0.3) \sigma_{\mathrm{R}}-(1.7 \pm 1.4) \sigma_{\mathrm{I}}, R^{2}=0.986 \\
E_{\mathrm{i}}(\mathrm{cp})([2.2 .2])=-(2.2 \pm 0.1)-(2.9 \pm 1.0) \sigma_{\mathrm{F}}- \\
(0.9 \pm 0.2) \sigma_{\mathrm{R}}-(1.7 \pm 0.9) \sigma_{\mathrm{I}}, R^{2}=0.973
\end{gathered}
$$

To compare the coefficients, the $E_{\mathrm{i}}(\mathrm{cp})$ values must be coded, ${ }^{42}$ for instance between $-1(-13.03$ and $-5.42 \mathrm{~kJ}$ $\left.\mathrm{mol}^{-1}\right)$ and $+1\left(-5.61\right.$ and $\left.-1.92 \mathrm{~kJ} \mathrm{~mol}^{-1}\right)$ :

$$
\begin{gathered}
E_{\mathrm{i}}(\mathrm{cp})(\text { benzenes })=(0.38 \pm 0.04)-(1.1 \pm 0.4) \sigma_{\mathrm{F}}- \\
(1.51 \pm 0.08) \sigma_{\mathrm{R}}-(0.5 \pm 0.4) \sigma_{\mathrm{I}}, R^{2}=0.986 \\
E_{\mathrm{i}}(\mathrm{cp})([2.2 .2])=(0.84 \pm 0.06)-(1.6 \pm 0.6) \sigma_{\mathrm{F}}- \\
(0.5 \pm 0.1) \sigma_{\mathrm{R}}-(1.0 \pm 0.5) \sigma_{\mathrm{I}}, R^{2}=0.973
\end{gathered}
$$

The bicyclo[2.2.2] octanes are more sensitive to field (1.6/1.1) and inductive (1.0/0.5) effects but much less sensitive to resonance effects $(0.5 / 1.51)$ than the benzene derivatives, as expected from the definition of the three $\sigma$ parameters (eqn (34) and (35)).

\section{Model 3. 3- and 4-Substituted pyridines}

The optimized geometries of the complexes between the 3- and 4-substituted pyridines with $\mathrm{FBr}$ and $\mathrm{ClBr}$ show a linear disposition of the dihalogen molecule with the nitrogen atom
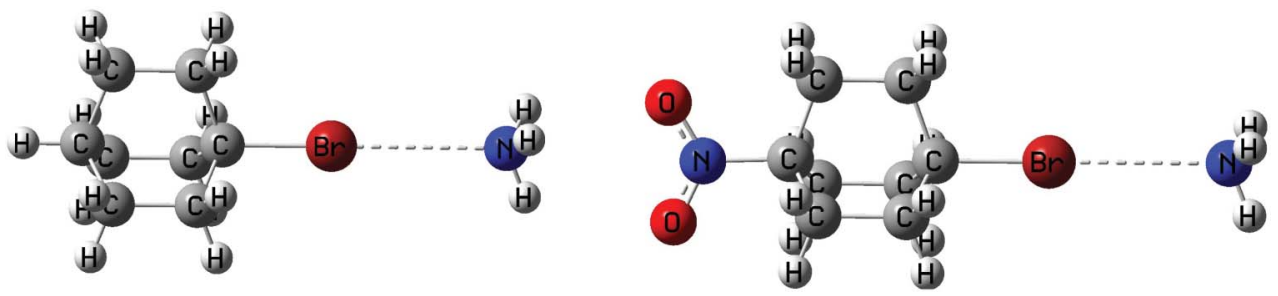

Fig. 3 Optimized structures of the parent and 4-nitro-1-bromobicyclo[2.2.2]octane with ammonia at the B97D/6-311+G(d) computational level. 
Table 4 Results obtained for the equation $E_{\mathrm{i}}(\mathrm{cp})\left(\mathrm{NH}_{3}\right)=a_{0}+a_{1}$ property of the 1-bromo-4-X-bicyclo[2.2.2]octane : $\mathrm{NH}_{3}$ complexes

\begin{tabular}{|c|c|c|c|c|c|c|}
\hline & $E_{i}$ & $\sigma_{\mathrm{F}}$ & $\mathrm{Br} \cdots \mathrm{N}$ & $\mathrm{C}-\mathrm{Br}$ & Br-radius & MEP-surface \\
\hline eqn & (26) & $(27)$ & $(28)$ & (29) & $(30)$ & (31) \\
\hline$R^{2}$ & 0.9997 & 0.897 & 0.984 & 0.969 & 0.983 & 0.993 \\
\hline SD & 0.02 & 0.34 & 0.13 & 0.19 & 0.14 & 0.09 \\
\hline$a_{0}$ & $1.99 \pm 0.03$ & $-2.1 \pm 0.1$ & $-210 \pm 7$ & $-588 \pm 27$ & $-527 \pm 18$ & $-2.63 \pm 0.03$ \\
\hline$a_{1}$ & $0.930 \pm 0.004$ & $-4.6 \pm 0.4$ & $64 \pm 2$ & $288 \pm 13$ & $253 \pm 9$ & $-254 \pm 5$ \\
\hline
\end{tabular}

of the pyridine (Fig. 4). The BSSE corrected interaction energies and intermolecular distances of these complexes are gathered in Table S5 in the ESI. $\dagger$ The interaction energies of the $\mathrm{FBr}$ complexes range between -73.7 and $-105.5 \mathrm{~kJ} \mathrm{~mol}^{-1}$ and those with $\mathrm{ClBr}$ between -47.1 and $-75.1 \mathrm{~kJ} \mathrm{~mol}^{-1}$. The interaction energies are in general slightly larger for a given substituent when it is located in position 4 compared to the values in position 3. The larger interaction energies in all the series correspond to the dimethylamino derivatives, $\mathrm{NMe}_{2}$, while the smaller ones are those of the nitro derivatives, $\mathrm{NO}_{2}$. The intermolecular distances range between 2.24 and $2.30 \AA$ in the complexes with $\mathrm{FBr}$ and between 2.33 and $2.44 \AA$ for the complexes with $\mathrm{ClBr}$. In accordance with the interaction energies, the shortest intermolecular distances are those of the $\mathrm{NMe}_{2}$ derivatives in each series and the longest are those of the $\mathrm{NO}_{2}$ derivatives.

A comparison of the interaction energies between the $\mathrm{FBr}$ and $\mathrm{ClBr}$ complexes show that they are highly correlated $\left(R^{2}\right.$ is 0.999 and 0.998 for the 3- and 4-substituted pyridines, respectively). However, when a similar comparison is carried out with the intermolecular distances, the correlation coefficients are not so high $\left(R^{2}\right.$ is 0.98 and 0.92 for the 3- and 4-substituted pyridines, respectively). The relationships between the interaction energies and the intermolecular distances, in contrast with the results obtained in the previous sections, are rather poor for the complexes between the 3-substituted pyridines and $\mathrm{FBr}$ and $\operatorname{ClBr}\left(R^{2}\right.$ of 0.55 and 0.58 , respectively) and slightly better for the complexes with the 4 -substituted pyridines ( $R^{2}$ of 0.87 and 0.98 , respectively).

The correlations between the $E_{\mathrm{i}}(\mathrm{cp})$ values of these complexes and the Hammett-Taft parameters (Table 5) show acceptable correlation coefficients $\left(R^{2}\right.$ between 0.907 and 0.921 ) when they are divided based on the XB donor and the 3- and 4-substituted derivatives (eqn (36)-(40), ESI $\dagger$ ). These coefficients worsen when all the complexes of $\mathrm{FBr}$ or $\mathrm{ClBr}$ are considered, presenting $R^{2}$ values of 0.83 and 0.84 respectively (eqn (38) and (41), ESI†).
As an electrostatic property associated with the monomers, the MEP minima of the lone pair of the pyridine derivatives has been considered in this case (Table 5). The smallest absolute value of the MEP corresponds to the $\mathrm{NO}_{2}$ derivative and the largest to the $\mathrm{NMe}_{2}$ one. These values show an acceptable linear correlation with the $\sigma_{\mathrm{m}}$ and $\sigma_{\mathrm{p}}$ parameters (0.95 and 0.93, respectively).

The $E_{\mathrm{i}}(\mathrm{cp})$ values of all the complexes studied in this section (68) have been correlated $v s$. the MEP minima of the pyridine and the $\sigma$-hole of the corresponding $\mathrm{FBr}$ or $\mathrm{ClBr}$ molecule (0.0844 and $0.504 \mathrm{au}$ ) using a similar relationship to the one reported in Table 3 for the bromobenzenes with different bases (Table 6). The results (eqn (42), ESI $\dagger$ ) are again excellent with a $\mathrm{SD}$ of $1.07 \mathrm{~kJ} \mathrm{~mol}^{-1}$, which represents between 1 to $2 \%$ of the $E_{\mathrm{i}}(\mathrm{cp})$ values obtained for these complexes $(-47.1$ to $-105.5 \mathrm{~kJ} \mathrm{~mol}^{-1}$ ) and a $R^{2}$ value of 0.996 .

\section{Model 4. Double-Hammett relationships}

In this section, we examine the complexes between the $p$ derivatives of 1-bromobenzene and 4-derivatives of pyridine (Scheme 3). Examples where both rings bear different substituents are not common in the literature. An interesting study by Hunter et al. discussed the double substituent effect in edge-to-face aromatic interactions stabilized by two hydrogen bonds. ${ }^{43,44}$

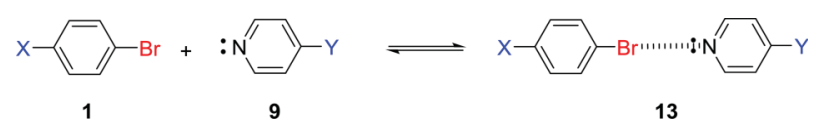

Scheme 3 Double-Hammett model.

All the possible complexes between 4-substituted 1-bromobenzenes and 4-substituted pyridines, taking into account the 17 substituents mentioned in Table 1, have been taken into
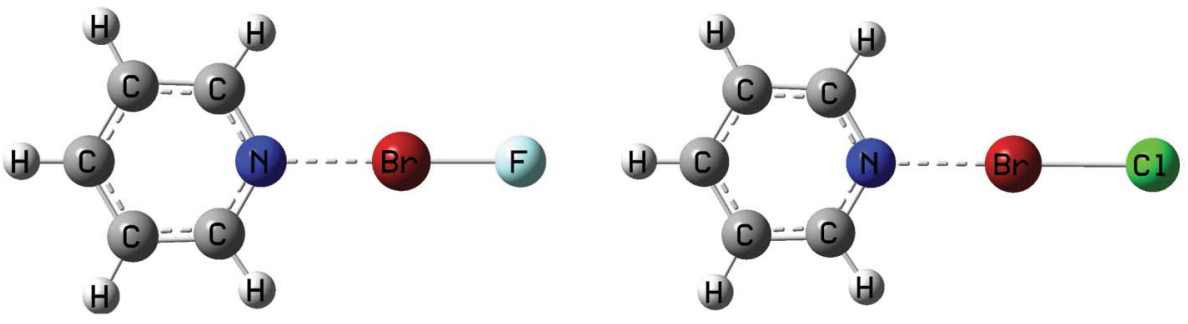

Fig. 4 Optimized geometry of the pyridine:FBr and pyridine: $\mathrm{ClBr}$ complexes at the B97D/6-311+G(d) computational level. 
Table 5 Statistical parameters of the correlations between the $E_{\mathrm{i}}(\mathrm{cp})$ values and the $\sigma_{\mathrm{m}}$ and/or $\sigma_{\mathrm{p}}$ parameters of the substituents $\left[E_{\mathrm{i}}(\mathrm{cp})=a_{0}+a_{1} \times\right.$ property]

\begin{tabular}{|c|c|c|c|c|c|c|}
\hline & FBr, 3-susb. Pyr. & FBr, 4-susb. Pyr. & All FBr & ClBr, 3-susb. Pyr. & ClBr, 4-susb. Pyr. & All ClBr \\
\hline eqn & $(36)$ & $(37)$ & $(38)$ & (39) & $(40)$ & $(41)$ \\
\hline$n$ & 17 & 17 & 34 & 17 & 17 & 34 \\
\hline$R^{2}$ & 0.921 & 0.907 & 0.834 & 0.921 & 0.920 & 0.843 \\
\hline $\mathrm{SD}$ & 2.30 & 2.45 & 3.24 & 2.05 & 2.06 & 2.81 \\
\hline Intercept $\left(a_{0}\right)$ & $-94.8 \pm 0.8$ & $-90.9 \pm 0.6$ & $-91.6 \pm 0.6$ & $-65.6 \pm 0.7$ & $-61.9 \pm 0.5$ & $-62.6 \pm 0.5$ \\
\hline Slope $\left(a_{1}\right)$ & $31 \pm 2$ & $16 \pm 1$ & $19 \pm 2$ & $28 \pm 2$ & $15.0 \pm 1$ & $18 \pm 1$ \\
\hline
\end{tabular}

account in this section $\left(17^{2}=289\right)$. Most of the complexes studied present a linear $\mathrm{C}-\mathrm{Br} \cdots \mathrm{N}$ disposition, with the two aromatic rings in an orthogonal arrangement. However, in 15 cases, the $\mathrm{C}-\mathrm{Br} \cdots \mathrm{N}$ disposition departs from linearity due to a secondary interaction between the $\mathrm{C}-\mathrm{H}$ group in position 2 of the pyridine and the electron rich region of the $\mathrm{Br}$ atom (Fig. 5). This situation is more common in complexes that are weakly bonded. The energetic difference between the minima with a non linear $\mathrm{C}-\mathrm{Br} \cdots \mathrm{N}$ disposition and those where the disposition of these three atoms has been forced to be linear is up to $0.95 \mathrm{~kJ} \mathrm{~mol}^{-1}$.

The AIM analysis of the complexes with a non linear C$\mathrm{Br} \cdots \mathrm{N}$ disposition present a bond critical point (BCP) between the $\mathrm{C}-\mathrm{H}$ group and the $\mathrm{Br}$ atom in some of the complexes but a ring critical point very close to the BCP is an indication that small changes in the geometry can result in the disappearance of the BCP.

In order to avoid the interference of this weak interaction, the interaction energy of the linearly forced complex has been considered for the 15 complexes with a non linear $\mathrm{C}-\mathrm{Br} \cdots \mathrm{N}$ disposition while in the rest of the cases, the optimized minima have been used. The BSSE corrected interaction energies of the 289 complexes studied (Table S7, ESI†) in this section range between -7.0 to $-16.8 \mathrm{~kJ} \mathrm{~mol}^{-1}$. For a given substituent on the benzene, the strongest complex corresponds to the 4-dimethylamine derivative of the pyridine and the weakest corresponds to the 4-nitro derivative. The opposite happens for a series of complexes where the substituent of the pyridine is fixed, in agreement with the results discussed in the previous sections.

The $E_{\mathrm{i}}(\mathrm{cp})$ values obtained in all the complexes have been correlated with the $\sigma_{\mathrm{p}}$ values of the substituents in the bromobenzenes, $\sigma_{\mathrm{p}}(\mathrm{X})$, the pyridine derivatives, $\sigma_{\mathrm{p}}(\mathrm{Y})$, and the product of both terms (eqn (43), ESI†, Table 7). In addition, and analogous to previous analysis, the values of the $\sigma$-hole of the isolated bromobenzenes and the MEP minima of the lone pair of the isolated pyridines have been taken into account (eqn (44), ESI $)$ ). The correlation with the $\sigma_{\mathrm{p}}$ parameters

Table 6 Statistical parameters of the correlation, $E_{\mathrm{i}}(\mathrm{cp})=a_{0}+a_{1} \times P_{1}+a_{2} \times P_{2}$ $+a_{12} \times P_{1} \times P_{2}$, between the $E_{i}(\mathrm{cp})$ values of all the complexes studied in this section (68), the MEP minimum of the pyridine $\left(P_{1}\right)$ and the $\sigma$-hole of the $\mathrm{Br}-\mathrm{Z}(\mathrm{Z}$ $=\mathrm{F}$ and $\mathrm{Cl})$ derivative $\left(P_{2}\right)$

$\begin{array}{llll}\text { eqn } & (42) & a_{0} & 34 \pm 5 \\ R^{2} & 0.996 & a_{1} & 570 \pm 54 \\ \text { SD } & 1.07 & a_{2} & -628 \pm 70 \\ N & 68 & a_{12} & 2402 \pm 776\end{array}$

provides acceptable results with $R^{2}$ values of 0.9 and an SD of $0.60 \mathrm{~kJ} \mathrm{~mol}{ }^{-1}$. As previously, the use of electrostatic parameters of the isolated molecules provides excellent correlations with a very small SD $\left(0.13 \mathrm{~kJ} \mathrm{~mol}^{-1}\right)$ and high values of $R^{2}(0.995)$.

\section{Summary and conclusions}

A theoretical DFT-B97D study of a large number of halogen bonded complexes is discussed in the present article. These complexes can be divided into four sets: i) 4 -substituted 1-iodo- and 1-bromobenzenes complexed with small bases $\left(\mathrm{NH}_{3}, \quad \mathrm{NCH}\right.$ and $\left.\mathrm{CNH}\right)$, ii) 4-substituted-1bromobicyclo[2.2.2] octanes: $\mathrm{NH}_{3}$, iii) 4-subtitued-pyridines with $\mathrm{FBr}$ and $\mathrm{ClBr}$, and iv) 4-substituted 1-bromobenzenes with 4 -substituted-pyridines. The total number of complexes studied is 459 .

The geometry and the interaction energies of the complexes have been statistically analyzed with substituent properties as those proposed by Hammett and Taft, with geometrical parameters ( $\mathrm{C}-\mathrm{Br}$ bond length and intermolecular distances) and electronic properties of the isolated monomers (bromine $\mathrm{vdW}$ radii in the interaction direction, $\sigma$-hole and MEP minima values). A list with all the equations and their corresponding statistics is reported in the ESI. $\dagger$

The Hammett-Taft approach provides reasonable statistical parameters with $R^{2}$ values of about 0.9 when compared to the $E_{\mathrm{i}}(\mathrm{cp})$ values in all the sets studied. Taking into account the large number of substituents for which these parameters are reported in the literature, it provides a basis to extend the initial prediction with a relatively small set of compounds to a large one with little effort.

The geometrical parameters and in particular, the ones derived from the electrostatic potential of the molecules, are able to provide excellent correlations when compared to the $E_{\mathrm{i}}(\mathrm{cp})$ values using the following equation:

$$
E_{\mathrm{i}}(\mathrm{cp})=a_{0}+a_{1} \times P_{1}+a_{2} \times P_{2}+a_{12} \times P_{1} \times P_{2}
$$

where $P_{1}$ is the $\sigma$-hole of the XB donor and $P_{2}$ is the MEP minima of the electron donor. In the series studied in the present article, small values of the SD [between 1 and $2 \%$ of the obtained $\left.E_{\mathrm{i}}(\mathrm{cp})\right]$ and high $R^{2}$ values $(>0.99)$ are obtained. Thus, these correlations can be used to estimate the interaction energies of new complexes with great accuracy 

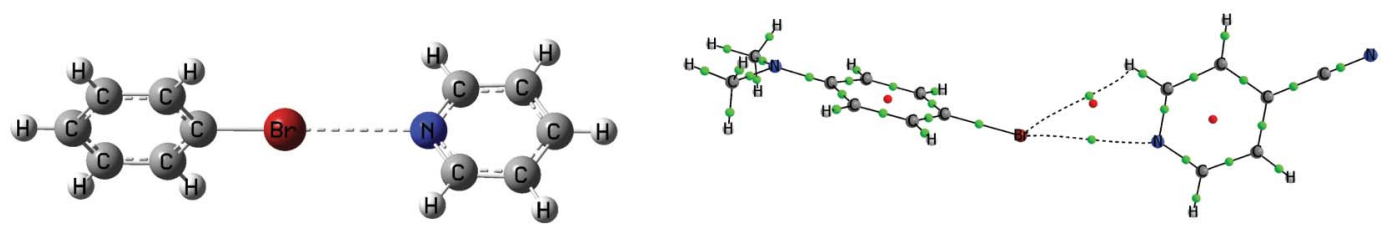

Fig. 5 Optimized geometry of the 1-bromobenzene:pyridine complex (left) and a molecular graph of one of the complexes with a non linear $\mathrm{C}-\mathrm{Br} \cdots \mathrm{N}$ disposition (right). The locations of the electron density bond and ring critical points are indicated with green and red spheres, respectively.

Table 7 Statistical analysis of the relationship between the $E_{\mathrm{i}}(\mathrm{cp})$ and the $\sigma_{\mathrm{p}}$ of the substituents and the electrostatic parameters of the isolated molecules ( $\sigma$-hole for the bromobenzenes and MEP minimum for the pyridine derivatives) using the equation: $E_{\mathrm{i}}(\mathrm{cp})=a_{0}+a_{1} \times P_{1}+a_{2} \times P_{2}+a_{12} \times P_{1} \times P_{2}$

\begin{tabular}{lll}
\hline & $P_{1}=\sigma_{\mathrm{p}}(\mathrm{X})$ & $P_{1}=\sigma$-hole \\
& $P_{2}=\sigma_{\mathrm{p}}(\mathrm{Y})$ & $P_{2}=$ MEP minimum \\
\hline eqn & $(43)$ & $(44)$ \\
$n$ & 289 & 289 \\
$R^{2}$ & 0.902 & 0.995 \\
$\mathrm{SD}$ & 0.60 & 0.13 \\
$a_{0}$ & $-9.88 \pm 0.04$ & $-12.0 \pm 0.2$ \\
$a_{1}$ & $-4.00 \pm 0.08$ & $332 \pm 10$ \\
$a_{2}$ & $1.13 \pm 0.08$ & $-78 \pm 2$ \\
$a_{12}$ & $2.21 \pm 0.18$ & $6351 \pm 105$ \\
& &
\end{tabular}

but this would require the calculation of the parameters of the isolated monomers in case they have not been previously reported. Additionally, new equations can be derived for new families of complexes using a small set of complexes and used to predict the interaction energy of many complexes within the family from the MEP properties of the isolated monomers, i.e., the monomers grow as the sum while the complexes grow as the product.

These results indicate that the electrostatic term of the interaction energy is able to explain the variability of the interaction energy within each family of compounds. The fact that different fitted $a_{i}$ parameters are obtained for each family indicates that the weight of other terms, such as polarization, dispersion and charge transfer, change among different families of complexes.

The satisfactory results obtained in this work would need additional research to be applied in non-ideal gas dispositions, such as those found in crystal structures. We would need to re-evaluate the $E_{\mathrm{i}}(\mathrm{cp})$ and the molecular descriptors in the function of the geometry of the complex in different dispositions in order to make the model more general.

\section{Acknowledgements}

We thank the Ministerio de Ciencia e Innovación (Project No. CTQ2009-13129-C02-02), the Spanish MEC (CTQ2007-62113) and the Comunidad Autónoma de Madrid (Project MADRISOLAR2, ref. S2009/PPQ-1533) for continuing support. Thanks are given to the CTI (CSIC) and CCC-UAM for the allocation of computing time.

\section{References}

1 (a) W. M. Latimer and W. H. Rodebush, J. Am. Chem. Soc., 1920, 42, 1419-1433; (b) L. Pauling, The Nature of the Chemical Bond and the Structure of Molecules and Crystals: An Introduction to Modern Structural Chemistry, Cornell University, Ithaca, N.Y., 1939; (c) G. A. Jeffrey, An Introduction to Hydrogen Bonding, Oxford University Press, Oxford, New York, 1997; (d) G. R Desiraju and T. Steiner, The Weak Hydrogen Bond: International Union of Crystallography, Oxford Science Publications, Oxford, 1999; (e) I. Rozas, I. Alkorta and J. Elguero, J. Am. Chem. Soc., 2000, 122, 11154-11161; (f) G. Gilli and P. Gilli, The Nature of the Hydrogen Bond: Outline of a Comprehensive Hydrogen Bond Theory: International Union of Crystallography, Oxford Science Publications, Oxford, 2009.

2 (a) T. B. Richarson, S. de Gala, R. H. Crabtree and P. E. M. Siegbahn, J. Am. Chem. Soc., 1995, 117, 12875-12876; (b) E. Peris, J. C. Lee, J. E. Rambo, O. Eisenstein and R. H. Crabtree, J. Am. Chem. Soc., 1995, 117, 3485-3491; (c) E. S. Shubina, N. V. Belkova, A. N. Krylov, E. V. Vorontsov, L. M. Epstein, D. G. Gusev, M. Niedermann and H. Berke, J. Am. Chem. Soc., 1996, 118, 1105-1112; (d) I. Alkorta, J. Elguero and C. Foces-Foces, Chem. Commun., 1996, 1633-1634; (e) I. Alkorta, F. Blanco, P. M. Deyà, J. Elguero, C. Estarellas, A. Frontera and D. Quiñonero, Theor. Chem. Acc., 2010, 126, 1-14; (f) I. Alkorta, J. Elguero, M. Solimannejad and S. J. Grabowski, J. Phys. Chem. A, 2011, 115, 201-210.

3 (a) K. Merz and V. Vasylyeva, CrystEngComm, 2010, 12, 3989-4002; (b) M. Erdélyi, Chem. Soc. Rev., 2012, 41, 3547-3557; (c) P. Politzer and J. S. Murray, Theor. Chem. Acc., 2012, 131, 1114 (1-10).

4 (a) R. M. Minyaev and V. I. Minkin, Can. J. Chem., 1998, 76, 776-788; (b) D. B. Werz, R. Gleiter and F. Rominger, J. Am. Chem. Soc., 2002, 124, 10638-10639; (c) C. Bleiholder, D. B. Werz, H. Köppel and R. Gleiter, J. Am. Chem. Soc., 2006, 128, 2666-2674; (d) M. Essefar, R. Herrero, E. Quintanilla, J. Z. Dávalos, P. Jiménez, J. L. Abboud, M. Yáñez and O. Mó, Chem.-Eur. J., 2007, 13, 1796-1803(erratum 2008, 14, 417); (e) G. Sánchez-Sanz, C. Trujillo, I. Alkorta and J. Elguero, ChemPhysChem, 2012, 13, 496-503.

5 (a) S. Zahn, R. Franck, E. Hey-Hawkins and B. Kirchner, Chem.Eur. J., 2011, 17, 6034-6038; (b) S. Tschirscwitz, P. Lönnecke and E. Hey-Hawkins, Dalton Trans., 2007, 1377-1382; (c) J. E. D. Bene, I. Alkorta, G. Sánchez-Sanz and J. Elguero, Chem. Phys. Lett., 2011, 512, 184-187; (d) S. Scheiner, J. Chem. Phys., 2011, 134, 943151-94315-9; (e) S. Scheiner, Chem. Phys., 2011, 387, 79-84; $(f)$ S. Scheiner, J. Phys. Chem. A, 2011, 115, 11202-11209.

6 (a) R. S. Mulliken and W. B. Person, Molecular Complexes, Wiley-Interscience, New York, 1969; (b) O. Hassel, Science, 1970, 170, 497-502. 
7 P. Metrangolo and G. Resnati, Halogen Bonding; Structure and Bonding, ed. D. M. P. Mingos, Springer-Verlag, Berlin Heidelberg, 2008, vol. 126.

8 (a) P. Politzer, J. S. Murray and P. Lane, Int. J. Quantum Chem., 2007, 107, 3046-3052; (b) P. Politzer, J. S. Murray and T. Clark, Phys. Chem. Chem. Phys., 2010, 12, 7748-7757; (c) P. Politzer, K. E. Riley, F. A. Bulat and J. S. Murray, Comput. Theor. Chem., 2012, 998, 2-8.

9 L. P. Hammett, J. Am. Chem. Soc., 1937, 59, 96-103.

10 (a) A. D. Campbell, S. Y. Chooi, L. W. Deady and R. A. Shanks, J. Chem. Soc. B, 1970, 1063-1065; (b) A. Krutosiková, J. Surá, J. Kovác and S. Juhás, Collect. Czech. Chem. Commun., 1975, 40, 3362-3369.

11 (a) M. H. Abraham, Chem. Soc. Rev., 1993, 22, 73-83; (b) M. Berthelot, C. Laurence, M. Safar and F. Besseau, J. Chem. Soc., Perkin Trans. 2, 1998, 283-290; (c) A. A. Oliferenko, P. V. Oliferenko, J. G. Huddleston, R. D. Rogers, V. A. Palyulin, N. S. Zefirov and A. R. Katritzky, J. Chem. Inf. Model., 2004, 44, 1042-1055.

12 Advances in Linear Free Energy Relationships, ed. N. B. Chapman and J. Shorter, Plenum Press, London and New York, 1972.

13 (a) S. Wold, Acta Chem. Scand., 1973, 27, 3602-3604; (b) J. E. Leffler and E. Grunwald, Rates and Equilibria of Organic Reactions as Treated by Statistical, Thermodynamic, and Extrathermodynamic Methods, Dover Publications, Mineola, N.Y., 1989.

14 Correlation Analysis in Chemistry., ed. N. B. Chapman and J. Shorter, Plenum Press, London and New York, 1978.

15 W. B. Person, W. C. Golton and A. I. Popov, J. Am. Chem. Soc., 1963, 85, 891-895.

16 (a) C. Laurence, M. Queignec-Cabanetos and B. Wojtkowiak, Can. J. Chem., 1983, 61, 135-138; (b) C. Laurence and J.-F. Gal, Lewis Basicity and Affinity Scales. Data and Measurement, John Wiley \& Sons, Chichester, UK, 2010; (c) C. Laurence, J. Graton, M. Berthelot and M. J. El Ghomari, Chem.-Eur. J., 2011, 17, 10431-10444.

17 C. Hansch, A. Leo and R. W. Taft, Chem. Rev., 1991, 91, 165-195.

18 A. Bauzá, D. Quiñonero, A. Frontera and P. M. Deyà, Phys. Chem. Chem. Phys., 2011, 13, 20371-20379.

19 (a) K. E. Riley, J. S. Murray, P. Politzer, M. C. Concha and P. Hobza, J. Chem. Theory Comput., 2009, 5, 155-163; (b) J. S. Murray, Z. P. Shields and P. Politzer, Int. J. Quantum Chem., 2010, 110, 2823-2832; (c) K. E. Riley, J. S. Murray, J. Fanfrlík, J. Řezáč, R. J. Solá, M. C. Concha, F. M. Ramos and P. Politzer, J. Mol. Model., 2011, 17, 3309-3318.

20 C. Hansch and A. Leo, Exploring QSAR, ACS Professional Reference Book., American Chemical Society, Washington, 1995.

21 L. P. Hammett, Physical Organic Chemistry, McGraw-Hill, New York, 1940.

22 http://www.wiredchemist.com/chemistry/data/hammettsigma-constants.

23 O. Exner and S. Böhm, J. Phys. Org. Chem., 2007, 20, 454-462.

24 O. Exner and S. Böhm, J. Phys. Org. Chem., 2006, 19, 393-401.
25 O. Exner and S. Böhm, Curr. Org. Chem., 2006, 10, 763-778.

26 T. M. Krygowski and B. T. Stepien, Chem. Rev., 2005, 105, 3482-3512.

27 W. P. Oziminski and J. C. Dobrowolski, J. Phys. Org. Chem., 2009, 22, 769-778.

28 W. P. Oziminski and T. M. Krygowski, J. Phys. Org. Chem., 2010, 23, 551-556.

29 C. H. Suresh, P. Alexander, K. P. Vijayalakshmi, P. K. Sajith and S. R. Gadre, Phys. Chem. Chem. Phys., 2008, 10, 6492-6499.

30 (a) J. A. Platts, Phys. Chem. Chem. Phys., 2000, 2, 3115-3120; (b) O. Lamarche and J. A. Platts, Chem.-Eur. J., 2002, 8, 457-466; (c) O. Lamarche and J. A. Platts, Chem. Phys. Lett., 2003, 367, 123-128.

31 S. Grimme, J. Comput. Chem., 2006, 27, 1787-1899.

32 M. J. Frisch, J. A. Pople, R. Krishnam and J. S. Binkley, J. Chem. Phys., 1984, 80, 3265-3269.

33 P. J. Hay and W. R. Wadt, J. Chem. Phys., 1985, 82, 270-283. 34 S. F. Boys and F. Bernardi, Mol. Phys., 1970, 19, 553-566.

35 M. J. Frisch, G. W. Trucks, H. B. Schlegel, G. E. Scuseria, M. A. Robb, J. R. Cheeseman, G. Scalmani, V. Barone, B. Mennucci, G. A. Petersson, H. Nakatsuji, M. Caricato, X. Li, H. P. Hratchian, A. F. Izmaylov, J. Bloino, G. Zheng, J. L. Sonnenberg, M. Hada, M. Ehara, K. Toyota, R. Fukuda, J. Hasegawa, M. Ishida, T. Nakajima, Y. Honda, O. Kitao, H. Nakai, T. Vreven, J. A. Montgomery Jr., J. E. Peralta, F. Ogliaro, M. Bearpark, J. J. Heyd, E. Brothers, K. N. Kudin, V. N. Staroverov, R. Kobayashi, J. Normand, K. Raghavachari, A. Rendell, J. C. Burant, S. S. Iyengar, J. Tomasi, M. Cossi, N. Rega, J. M. Millam, M. Klene, J. E. Knox, J. B. Cross, V. Bakken, C. Adamo, J. Jaramillo, R. Gomperts, R. E. Stratmann, O. Yazyev, A. J. Austin, R. Cammi, C. Pomelli, J. W. Ochterski, R. L. Martin, K. Morokuma, V. G. Zakrzewski, G. A. Voth, P. Salvador, J. J. Dannenberg, S. Dapprich, A. D. Daniels, Ö. Farkas, J. B. Foresman, J. V. Ortiz, J. Cioslowski and D. J. Fox, Gaussian 09, Revision A.2, Gaussian, Inc., Wallingford CT, 2009.

36 F. A. Bulat, A. Toro-Labbé, T. Brinck, J. S. Murray and P. Politzer, J. Mol. Model., 2010, 16, 1679-1691.

37 R. F. W. Bader, M. T. Carroll, J. R. Cheeseman and C. Chang, J. Am. Chem. Soc., 1987, 109, 7968-7979.

38 F. W. Bieger-Konig, R. F. W. Bader and T. H. Tang, J. Comput. Chem., 1982, 3, 317-328.

39 T. A. Keith and T. K. Gristmill, Software, AIMAll (Version 12.09.23), Overland Park KS, USA, 2012 (aim.tkgristmill.com).

40 (a) A. P. Harding and P. L. A. Popelier, Phys. Chem. Chem. Phys., 2011, 13, 11264-11282; (b) A. P. Harding and P. L. A. Popelier, Phys. Chem. Chem. Phys., 2011, 13, 11283-11293.

41 NIST: http://webbook.nist.gov/chemistry/.

42 (a) R. Carlson, Design and Optimization in Organic Synthesis, Elsevier, Amsterdam, 1992; (b) G. Sánchez-Sanz, I. Alkorta and J. Elguero, Comput. Theor. Chem., 2011, 974, 37-42.

43 F. J. Carver, C. A. Hunter, D. J. Livingstone, J. F. McCabe and E. M. Seward, Chem.-Eur. J., 2002, 8, 2849-2859.

44 M. Lewis, C. Bagwill, L. K. E. Hardebeck and S. Wireduaah, Comput. Struct. Biotech. J., 2012, 1, e201204004http:// dx.doi.org/10.5936/csbj.200204004. 